\title{
Efficient Multicomponent Catalyst-Free Synthesis of Substituted 2-Aminopyridines ${ }^{\dagger}$
}

\author{
Djamila Benzenine 1,2, , Zahira Kibou 2,3, Fatima Belhadj 2,4, Ikram Baba-Ahmed 1,2, M. Pilar Vázquez-Tato ${ }^{4}$, \\ Julio A. Seijas ${ }^{4}$ and Noureddine Choukchou-Braham ${ }^{2}$
}

Citation: Benzenine, D.; Kibou, Z.;

Belhadj, F.; Baba-Ahmed, I.;

Vázquez-Tato, M.P.; Seijas, J.A.;

Choukchou-Braham, N. Efficient

Multicomponent Catalyst-Free

Synthesis of Substituted

2-Aminopyridines. Chem. Proc. 2021,

3, 125. https://doi.org/10.3390/

ecsoc- $24-08381$

Academic Editors: Julio A. Seijas and M. Pilar Vázquez-Tato

Published: 14 November 2020

Publisher's Note: MDPI stays neutral with regard to jurisdictional claims in published maps and institutional affiliations.

Copyright: (c) 2020 by the authors. Licensee MDPI, Basel, Switzerland. This article is an open access article distributed under the terms and conditions of the Creative Commons Attribution (CC BY) license (http://creativecommons.org/licenses /by/4.0/).
1 Laboratoire de Chimie Appliquée, Centre Universitaire Belhadj Bouchaib de Ain Témouchent, B.P. 284, Ain Témouchent 46000, Algeria; i_babaahmed@yahoo.com

2 Laboratoire de Catalyse et Synthèse en Chimie Organique, Faculté des Sciences, Université de Tlemcen, B.P.119, Tlemcen 13000, Algeria; zahira_kibou@yahoo.fr (Z.K.); fbelhadj88@yahoo.fr (F.B.); nbchoukchou@yahoo.fr (N.C.-B.)

3 Faculté de Médecine, Université Oran 1, B.P. 1510 El Menaouar, Oran 31000, Algeria

4 Departamento de Química Orgánica, Facultad de Ciencias, Universidad of Santiago De Compostela, Alfonso X elSabio, 27002 Lugo, Spain; pilar.vazquez.tato@usc.es (M.P.V.-T.); julioa.seijas@usc.es (J.A.S.)

* Correspondence: benzeninedjamila@gmail.com

+ Presented at the 24th International Electronic Conference on Synthetic Organic Chemistry, 15 November-15 December 2020; Available online: https://ecsoc-24.sciforum.net/.

Abstract: 2-aminopyridines scaffolds are an important class of nitrogen heterocyclic compounds with a wide range of biological activities. Multicomponent reactions (MCRs) are useful methods for the construction of nitrogen heterocyclic compounds. In this context, syntheses of 2-aminopyridines derivatives via MCRs have attracted considerable attention in recent years. We present, in this work, a rapid and efficient synthesis of 2-aminopyridine derivatives, via the catalyst-free four-component method. This protocol provides a simple and practical approach to functionalized 2-aminopyridnes from readily available substrates under solvent-free conditions.

Keywords: 2-aminopyridine; catalyst free; solvent-free; green conditions; MCRs

\section{Introduction}

The development of new methods for the synthesis of nitrogenous heterocyclic compounds presents a great challenge in organic synthesis and in medicinal chemistry [1]. 2-Aminopyridines are promising substituted pyridines that have been shown to be biologically active molecules. Additionally, 2-aminopyridines are often used as ligands in inorganic and organometallic chemistry because of their chelating abilities. They could potentially serve, if substituted with optically active groups, as chiral auxiliaries or chiral ligands in asymmetric reactions [2,3]. For these reasons, 2-aminopyridines are valuable synthetic targets. Due to their high pharmacologic interests, there are a considerable number of synthetic methods that have been described in the literature for a long time [1,3-5].

Recently, the use of solvent-free methods has become a very powerful green chemical technology procedure from both the economical and synthetic points of view. There is also another route to combine economic aspects with the environmental, that is, the multicomponent reaction [6].

In this context, we present here an efficient multicoponent catalyst-free synthesis of substituted 2-aminopyridines (Figure 1). This green approach was developed using readily available compounds, inexpensive, and free solvent conditions. 
<smiles>[R]c1cc([R])c(C#N)c(N)n1</smiles>

Figure 1. Structure of 2-aminopyridines.

\section{Results and Discussion}

In the present study, a novel and efficient procedure for the synthesis of 2aminopyridines has been presented. In connection with our recent investigation on the synthesis of nitrogen heterocycles under solvent-free conditions, we describe here a multicomponent method for the synthesis of 2-aminopyridines efficiently without a catalyst. This approach is a process in which four easily accessible components are combined in a single reaction to produce a final product. Initially, a model reaction was conducted using acetophenone $(0.1 \mathrm{~mol})$, malononitrile $(0.1 \mathrm{~mol})$, benzaldehyde $(0.1 \mathrm{~mol})$, and ammonium carbonate $(0.1 \mathrm{~mol})$ at room temperature under solvent-free conditions (Table 1). The product is confirmed by NMR, IR, and MS analyses.

Table 1. Optimization of conditions.

$\frac{\frac{\mathbf{R}_{1}}{\mathrm{C}_{6} \mathrm{H}_{5}-}}{4-\mathrm{Cl}_{2}-\mathrm{C}_{6} \mathrm{H}_{4-}}$

a: room temperature; ${ }^{\text {b: }} 80^{\circ} \mathrm{C}$.

In order to evaluate the generality of this model reaction, we were encouraged to extend this reaction to a variety of acetophenones, so we have examined this reaction employing the optimized conditions. As a result, we found that using the heating method gives good yields (Table 2).

Table 2. Synthesis of 2-aminopyridines.

\begin{tabular}{ccc}
\hline $\mathbf{R}_{1}$ & $\mathbf{R}_{2}$ & Yield (\%) \\
\hline $\mathrm{C}_{6} \mathrm{H}_{5-}$ & & \\
$\mathrm{p}-\mathrm{Cl}_{-}-\mathrm{C}_{6} \mathrm{H}_{4-}$ & & $65^{\mathrm{a}} ; 80^{\mathrm{b}}$ \\
$\mathrm{p}-\mathrm{CH}_{3} \mathrm{C}_{6} \mathrm{H}_{4-}$ & $4-\mathrm{Cl}_{-} \mathrm{C}_{6} \mathrm{H}_{4}$ & 50 a; $90^{\mathrm{b}}$ \\
$\mathrm{m}-\mathrm{CH}_{3} \mathrm{OCC}_{6} \mathrm{H}_{4-}$ & & $45 \mathrm{a} ; 88^{\mathrm{b}}$ \\
$2,4-\mathrm{Cl}_{-} \mathrm{C}_{6} \mathrm{H}_{3}-$ & & $58 \mathrm{a} ; 95^{\mathrm{b}}$ \\
\hline
\end{tabular}

a: room temperature; ${ }^{\text {b: }} 80^{\circ} \mathrm{C}$.

\section{Experimental Procedure}

Herein, we describe a simple and efficient synthesis of 2-aminopyridines derivatives under solvent-free conditions.

General procedure: A mixture of acetophenone derivatives $(0.1 \mathrm{~mol})$, malononitrile ( $0.1 \mathrm{~mol})$, 4-Cl-benzaldehyde $(0.1 \mathrm{~mol})$, and $(0.1 \mathrm{~mol})$ of ammonium carbonate was stirred at room temperature under solvent-free conditions. After cooling, the solid obtained was washed several times with diethyl ether to give 2-aminopyridines derivatives.

\section{Conclusions}

We have developed an efficient synthesis of 2-aminopyridines via a reaction between acetophenone derivatives, malononitrile, aldehyde derivatives, and ammonium carbonate. The compound's structure is confirmed by spectral analysis. This approach 
includes some advantages such as mild reaction conditions, high yields, and an environmentally friendly process. The simplicity of this synthetic route will offer an attractive alternative to conventional methods.

Acknowledgments: The authors wish to thank Directorate General for Scientific Research and Technological Development (DGRSDT), the University of Tlemcen and the University of Ain Témouchent for the financial support. We also thank the Ministerio de Economía, Industria y Competitividad (Spain) (Project MAT2017- 86109-P) for financial support.

\section{References}

1. Cheikh, N.; Bachir, K.; Benabdallah, M.; Villemin, D. A new route for the synthesis of 2-aminopyridines. Sci. Stud. Res. Chem. Chem. Eng. 2011, 12, 121-126.

2. Pasumansky, L.; Hernández, A.R.; Gamsey, S.; Goralski, C.T.; Singaram, B. Synthesis of aminopyridines from 2-fluoropyridine and lithium amides. Tetrahedron Lett. 2004, 45, 6417-6420.

3. Tu, S.; Jiang, B.; Zhang, Y.; Jia, R.; Zhang, J.; Yao, C.; Shi, F. An efficient and chemoselective synthesis of N-substituted 2-aminopyridines via a microwave-assisted multicomponent reaction. Organ. Biomol. Chem. 2007, 5, 355-359.

4. Guo, K.; Thompson, M.J.; Reddy, T.R.; Mutter, R.; Chen, B. Mechanistic studies leading to a new procedure for rapid, microwave assisted generation of pyridine-3, 5-dicarbonitrile libraries. Tetrahedron 2007, 63, 5300-5311.

5. Poola, B.; Choung, W.; Nantz, M.H. A mild, catalyst-free synthesis of 2-aminopyridines. Tetrahedron. 2008, 64, 10798-10801.

6. Kibou, Z.; Cheikh, N.; Villemin, D.; Choukchou-Braham, N. A rapid synthesis of highly functionalized 2-pyridones and 2-aminopyridines via a microwave-assisted multicomponent reaction. J. Mater. Environ. Sci. 2016, 7, 3061-3067. 